DOI: $10.20472 / B M .2019 .7 .1 .005$

\title{
FINANCIAL TRANSACTIONS THROUGH BANKING AGENCY SELECTIONS IN THAILAND
}

\author{
NARIN LOETRUEANGNAPHA, TANPAT KRAIWANIT
}

\begin{abstract}
:
This quantitative research is based on the data collected from an online questionnaire completed by a representative sample of 860 respondents; the Discriminant Analysis was used for data analysis and to create the group classification equation. The findings demonstrated that the factors influencing the selection of banking agents include age, career, marital status, savings, frequency of counter service uses, opinion of agent system and overall banking agent. These variables were used to form a model function of group selection. Furthermore, unstandardized discriminant equations were used to predict group membership, with 70.8 percent predicting correctly. Apart from this, our suggestion for future studies is to observe a population differing in age because each person has different opportunities and, as such, a different potential to access the new technology. Since opinions of banking agents played an important role in this study, financial institutions must ensure that the safety policies protecting banking agents' clients are of the same standards as those of the appointing financial institutions.
\end{abstract}

\section{Keywords:}

Financial Transaction, Banking Agent, Agent Selection

JEL Classification: $A 14, G 20, G 29$

\section{Authors:}

NARIN LOETRUEANGNAPHA, RANGSIT University, Thailand, Email: narin.160@rsu.ac.th TANPAT KRAIWANIT, RANGSIT University, Thailand, Email: tanpat.k@rsu.ac.th

\section{Citation:}

NARIN LOETRUEANGNAPHA, TANPAT KRAIWANIT (2019). FINANCIAL TRANSACTIONS THROUGH BANKING AGENCY SELECTIONS IN THAILAND . International Journal of Business and Management, Vol. VII(1), pp. 63-73., 10.20472/BM.2019.7.1.005 


\section{Introduction}

Technological changes have influenced the banking industry to such an extent that every company is trying to maintain its existing customer base and accelerate the expansion of a new customer base, causing intense competition. Therefore, many banks have developed financial products and services which meet clients' needs and create the best customer satisfaction in order to attract customers leading to decreasing costs. One of the recent reliable technologies which the banks use to connect and service their customers who live far from bank branches is mobile banking or internet banking. The growth of mobile banking has not only increased the number of client accounts but also increased the volume and total value of the software; hence, mobile banking is necessary for continuous improvements in banking services. The changes in user behaviour regarding financial transactions has led many commercial banks to adapt to this change by creating a full range of financial services in every online channel, together with improving the safety of the online system. Nowadays, the number of internet banking users is increasing day-by-day, so this phenomenon has caused many commercial bank branches to close in recent years because the role of the physical branches is reduced and the costs of each branch, such as rental fees, employee salaries, electric bills and other expenses, are increasing. Therefore, it is not worth the investment, especially branches not located in shopping malls since there are only a few clients visiting the banks during business hours. According to the aforementioned reasons, this research is interested in studying the financial transactions achieved through banking agents, which are currently being provided by many providers such as the local commercial banks of Thailand, e.g. Kasikorn Bank, Krung Thai Bank and Bangkok Bank, etc. The aims of this study are to study people's attitudes towards the changes of financial institutions in providing banking services through banking agents, to handle the positive and negative impacts of banking services provided by the banking agents and to apply the findings to implement service improvements and other further applications.

\section{Conceptual Framework}

Independent Variables are customers' personal information, including gender, age, education, career, monthly income, savings and attitude to banking agents.

Dependent Variable is the awareness and the use of banking agents (e.g. Post Office, 7Eleven, Boon Term and Term Sa bye) to conduct financial transactions.

\section{Terms and Definitions}

Banking agent: This is a juristic person who is assigned by a financial institution (Bank of Thailand, n.d.) to act on behalf of a bank to provide financial services to customers under the Bank of Thailand's guidelines and conditions of approval.

Post office: This is a banking agent approved by six or seven local banks that are situated in every local administrative government, particularly in rural areas. (Thairathonline, 2011)There are 1,700 branches which implement bank@post services such as opening new accounts, withdrawals, deposits and money transfers.

7- Eleven: Convenience stores like 7-Eleven )Sanguanprasit, 2018) can provide financial services because there are counter services staffed by banking agents (the representatives of the bank) where the clients are able to withdraw, deposit and transfer money through 13,000 available counters.

Boon Term: Forth Smart Service Public Company Limited has the largest network in Thailand through "Boon Term Online Top-Up Machine" which is spread over 130,000 units nationwide (Boonterm, 2015); therefore, Boon Term is a convenient method which achieves the demands 
of bank customers who want to access the banking services, including deposits and money transfer services, 24/7.

Term Sa bye: The highlight of this online top-up cabinet (TermSabyeplus, n.d.) is kiosks prepaid with different functions and services. These top-up cabinets are installed in front of many convenience stores and are appointed by two local banks for transferring money only.

\section{Methodology}

The population in this study is a group of people who have often used the bank counter services and the samples are selected by the non-probability sampling technique called the convenience selection. The data was collected via an online questionnaire which was completed perfectly and subsequently checked to ensure the information was accurate. The gathered data was then analysed by discriminant analysis methods to identify a set of prediction equations based on the independent variables used to classify individuals into groups (Bruin, J. 2006). There are two possible objectives in using the discriminant analysis: (1) finding a predictive equation to classify new individuals and (2) interpreting the predictive equation to better understand the relationships that may exist among the variables. In discriminant analyses, the dependent variable must be a "categorical variable". The values of a categorical variable serve only to named groups. This means a subject can belong to one and only one of the groups indicated by the categorical variable.

\section{Results}

The results from the 860 respondents who answered the questions regarding the awareness and use of four bank agents are shown in the following tables:

Table 1: A post office as a banking agent

\begin{tabular}{ccc}
\hline Awareness and/or Use & Frequency & Percent \\
\hline Not known about a banking agent & 96 & 11.2 \\
Known but not used & 389 & 45.2 \\
Known and used & 375 & 43.6 \\
Total & 860 & 100.0 \\
\hline
\end{tabular}

Table 1 reveals that 45.2 per cent of people knew about, but had not used, a post office as a banking agent, while 45.2 per cent of people knew about and had used a post office as a banking agent.

Table 2: A 7-Eleven (Counter Service) as a banking agent

\begin{tabular}{ccc}
\hline Awareness and/or Use & Frequency & Percent \\
\hline Not known about a banking agent & 45 & 5.2 \\
Known but not used & 237 & 27.6 \\
Known and used & 578 & 67.2 \\
Total & 860 & 100.0 \\
\hline
\end{tabular}


Table 2 shows that the percentage of respondents who knew about and used a 7-Eleven (Counter Service) as a banking agent accounts for 67.2 per cent, whereas 27.6 percent of people knew about but had not used a Counter Service as a banking agent.

Table 3: A Boon Term as a banking agent

\begin{tabular}{ccc}
\hline Awareness and/or Use & Frequency & Percent \\
\hline Not known about a banking agent & 111 & 12.9 \\
Known but not used & 378 & 45.0 \\
Known and used & 362 & 42.1 \\
Total & 860 & 100.0 \\
\hline
\end{tabular}

Table 3 illustrates the percentage of respondents who had known about but not used a Boon Term as a banking agent accounts for 45.0 per cent, while 42.1 per cent of people knew about and had used a Boon Term as a banking agent.

Table 4: A Term Sa Bye as a banking agent

\begin{tabular}{ccc}
\hline Awareness and/or Use & Frequency & Percent \\
\hline Not known about a banking agent & 99 & 11.5 \\
Known but not used & 482 & 56.0 \\
Known and used & 279 & 32.4 \\
Total & 860 & 100.0 \\
\hline
\end{tabular}

Table 4 indicates that the percentage of respondents who had known about but not used a Term Sa Bye as a banking agent amounted to 56.0 per cent, while 32.4 percent of people had known about and used a Term Sa Bye as a banking agent.

As this research used discriminant analysis to test its hypotheses regarding the classification of four banking agents, including post office, 7-Eleven, Boon Term and Term sa bye, it is necessary to screen respondents who used only one service. The dependent variable stated that respondents must be a member of only one group, so the sample who met the criterion for the analysis totalled 480 users, meaning the rest used more than one banking agent. The findings are shown in the following table.

Table 5: Banking agent (meet criterion for analysis)

\begin{tabular}{ccc}
\hline Banking agents & Frequency & Percent \\
\hline Post office & 48 & 10.0 \\
7-Eleven & 296 & 61.7 \\
Boon term & 58 & 12.1 \\
Term-sa-bye & 78 & 16.3 \\
Total & 480 & 100.0
\end{tabular}


In Table 5, the findings show that 7-Eleven is the most popular banking agent, accounting for 61.7 percent of users, followed by Term-sa-bye, Boon term and post office, accounting for 16.3 percent, 16.3 percent and 10.0 percent, respectively.

In weighting personal factors to be numeric independent variables in the hypotheses, the deployment for scoring can be shown in the following table:

Table 6: Weighting personal factors by Chi-square value

\begin{tabular}{ccc}
\hline Personal Data & Chi-square Value & Weighted Score \\
\hline Age & 307 & 30 \\
Education & 65 & 6 \\
Status & 101 & 10 \\
Income & 128 & 13 \\
Savings & 216 & 21 \\
Career & 207 & 20 \\
Total & 1024 & 100 \\
\hline
\end{tabular}

From Table 6, the proportion of personal factors weighting values and the total Chi-square value indicates that the highest points are age, amounting to (30), followed by savings (21), career (20), income (13), status (10) and education (6).

Table 7: Personal factors scoring allocation

\begin{tabular}{cccc}
\hline AGE & Frequency & Percent & Weight \\
\hline Under 20 years & 144 & 30.0 & 8.99 \\
20-29 years & 136 & 28.3 & 8.48 \\
30-39 years & 60 & 12.5 & 3.75 \\
40-49 years & 88 & 18.3 & 5.49 \\
50 years and over & 52 & 10.8 & 3.24 \\
Total & 480 & 100.0 & 30 points \\
\hline EDUCATION & Frequency & Percent & Weight \\
\hline Undergraduate & 222 & 46.3 & 2.94 \\
Bachelor's degree & 212 & 44.2 & 2.81 \\
Master's or higher & 46 & 9.6 & 0.61 \\
Total & 480 & 100.0 & 6 points \\
STATUS & Frequency & Percent & Weight \\
Single & 358 & 74.6 & 7.36 \\
Married & 120 & 25.0 & 2.47 \\
\hline Total & 2 & .4 & 0.04 \\
Widowed/divorced/separated & 480 & 100.0 & 10 points \\
\hline Under 10,000 baht & Frequency & Percent & Weight \\
\hline THLY INCOME & 172 & 35.8 & 4.475
\end{tabular}




\begin{tabular}{cccc} 
10,001-20,000 baht & 186 & 38.8 & 4.85 \\
20,001-30,000 baht & 98 & 20.4 & 2.55 \\
30001-40000 baht & 24 & 5.0 & 0.625 \\
Total & 480 & 100.0 & 13 points \\
\hline SAVINGS PER MONTH & Frequency & Percent & Weight \\
\hline 3000 baht and under & 206 & 42.9 & 9.05 \\
3001-6000 baht & 110 & 22.9 & 4.83 \\
6000-12000 Baht & 122 & 25.4 & 5.36 \\
More than 12000 baht & 42 & 8.8 & 1.86 \\
Total & 480 & 100.0 & 21 points \\
\hline CAREER & Frequency & Percent & Weight \\
\hline Government officers/employees of state & 24 & 5.0 & 1.01 \\
enterprises & 140 & 29.2 & 5.90 \\
Company employees/contractors & 48 & 10.0 & 2.02 \\
Business owner/self-employed & 26 & 5.4 & 1.09 \\
Tenant/freelancer & 242 & 50.4 & 10.19 \\
Student & 480 & 100.0 & 20 points \\
Total & & &
\end{tabular}

The independent variables for discriminant analysis are assumed to have linear relations with the independent variables. If one of the independent variables has a high correlation with another or is a function (e.g., the sum) of other independents, the tolerance value for that variable will approach 0 and the matrix will not have a unique discriminant solution. There must also be low multicollinearity of the independents, as shown in the following table:

Table 8: Test of collinearity between independent variables

\begin{tabular}{ccc}
\hline \multirow{2}{*}{ Independent Variables } & \multicolumn{2}{c}{ Collinearity Statistics } \\
\cline { 2 - 3 } & Tolerance & VIF \\
\hline Frequency of counter use & .439 & 2.276 \\
Opinion of agent system & .533 & 1.877 \\
Opinion of overall bank agent & .779 & 1.284 \\
Age & .171 & 5.859 \\
Education & .335 & 2.986 \\
Marital Status & .385 & 2.594 \\
Income & .530 & 1.888 \\
Savings & .351 & 2.848 \\
Career & .315 & 3.173 \\
\hline
\end{tabular}


Table 8 demonstrates that the variance inflation factor (VIF) values are, broadly, not above 5 , with the exception of age, which has a tolerance value close to 0 . The VIF values of more than 4 or 5 are sometimes regarded as being moderate to high, with values of 10 or more being regarded as very high (Bock, 2018). This means that the independent variables have no collinearity problems; however, age may cause a slight collinearity impact to this study, although it would not be problematic.

Discriminant analysis is highly sensitive to the heterogeneity of variance-covariance matrices among independent mean groups; therefore, before accepting the final conclusions in a critical study, the equality of group means need to be tested as represented in the following table.

Table 9: Tests of equality of group means

\begin{tabular}{cccccc}
\hline Independent Variables & Wilks' Lambda & $\mathrm{F}$ & $\mathrm{df1}$ & $\mathrm{df2}$ & Sig. \\
\hline Frequency of counter use & .929 & 11.573 & 3 & 452 & .000 \\
Opinion of agent system & .737 & 53.700 & 3 & 452 & .000 \\
Opinion of overall bank agent & .971 & 4.470 & 3 & 452 & .004 \\
Age & .567 & 114.866 & 3 & 452 & .000 \\
Education & .961 & 6.139 & 3 & 452 & .000 \\
Marital Status & .765 & 46.253 & 3 & 452 & .000 \\
Income & .851 & 26.343 & 3 & 452 & .000 \\
Savings & .807 & 36.146 & 3 & 452 & .000 \\
Career & .712 & 60.952 & 3 & 452 & .000 \\
\hline
\end{tabular}

Table 9 conveys that all independent variable group means are different at the significance level of 0.05 . This is not in line with previous assumptions, or else there is a violation of the assumption. Furthermore, this also assumes that minor deviations are not important and will not have a problematic effect on the prediction of discriminant function.

Table 10: Variables in the discriminant analysis

\begin{tabular}{cccc}
\hline Independent Variables & Tolerance & F to Remove & Wilks' Lambda \\
\hline Age & .367 & 29.072 & .417 \\
Opinion of agent system & .686 & 25.557 & .409 \\
Career & .423 & 10.479 & .373 \\
Saving & .436 & 9.559 & .371 \\
Marital Status & .517 & 13.320 & .380 \\
Frequency in using counters & .720 & 9.887 & .372 \\
Opinion of overall bank agent & .822 & 2.571 & .355
\end{tabular}

The findings in Table 10 insignificant two of the independent variables, education and income, from being variables in the analysis; the other seven variables were remained in the discriminant analysis. 
Table 11: Wilks' Lambda test of coefficient significance

\begin{tabular}{ccccc}
\hline Test of Function(s) & Wilks' Lambda & Chi-square & df & Sig. \\
\hline 1 through 3 & .349 & 473.411 & 21 & .000 \\
2 through 3 & .741 & 134.584 & 12 & .000 \\
3 & .950 & 23.176 & 5 & .000 \\
\hline
\end{tabular}

From Table 11, Wilks' Lambda indicates the significance of the discriminant function, as shown in the following table.

Table 12: Discriminant function coefficients

\begin{tabular}{cccc}
\hline \multirow{2}{*}{ Independent Variables } & \multicolumn{3}{c}{ Function } \\
\cline { 2 - 4 } & 1 & 2 & 3 \\
\hline Frequency in counter using & -.064 & -.387 & .230 \\
Opinion of agent's system & -.732 & 1.689 & -1.516 \\
Opinion of bank agent & -.315 & -.130 & .544 \\
Age & .445 & .447 & -.557 \\
Marital Status & .217 & .233 & -.376 \\
Savings & -.151 & .056 & .660 \\
Career & .068 & -.267 & .217 \\
(Constant) & -.409 & -7.819 & 3.291 \\
\hline
\end{tabular}

Unstandardised coefficients

From Table 12, the discriminant function coefficients illustrate the following three unstandardised equations:

$D_{1}=-.409+.068$ Career-.151 Saving +.217 Marital Status+.445Age -.315 Opinion to bank agent-.732 Opinion to agent's system-.064 Frequency in counter using $\mathrm{D}_{2}=-7.819-.267$ Career+.056 Savings +.233 Marital Status +.447 Age -.130 Opinion to bank agent1.689 Opinion to agent's system-.387 Frequency in counter $\mathrm{D}_{3}=3.291+.217$ Career+.660Savings -.376 Marital Status-.557Age +.544 Opinion to bank agent-1.516 Opinion to agent's system+.230 Frequency in counter

Table 13: Classification results (a)

\begin{tabular}{cccccc}
\hline \multirow{2}{*}{ Original (Count) } & \multicolumn{4}{c}{ Predicted Group Membership } & \multirow{2}{*}{ Total } \\
\cline { 2 - 5 } & Post Office & 7-Eleven & Boon Term & Term Sa Bye & \\
\hline Post Office & $24(50.0 \%)$ & $0(0.0 \%)$ & $24(50.0 \%)$ & $0(0.0 \%)$ & $48(100 \%)$ \\
7-Eleven & $18(6.1 \%)$ & $230(77.7 \%)$ & $30(10.1 \%)$ & $18(6.1 \%)$ & $296(100 \%)$ \\
Boon Term & $8(13.8 \%)$ & $0(0.0 \%)$ & $50(86.2 \%)$ & $0(0.0 \%)$ & $58(100 \%)$ \\
Term Sa Bye & $6(7.7 \%)$ & $0(0.0 \%)$ & $36(46.2 \%)$ & $36(46.2 \%)$ & $78(100 \%)$ \\
\hline
\end{tabular}

(a) 70.8 of original grouped cases correctly classified. 
From Table 13, we can see that the discriminant unstandardised equations detailed in Table 12 correctly predict 70.8 per cent of group membership.

\section{Discussions and Conclusions}

The findings reveal that the age, marital status, savings, career, frequency of counter use, opinion of agent system and opinion of bank agent factors have an influence on the selection of financial transactions through banking agents. The characteristics of the customers (Malek et al., 2017) who use the services are different. Career and age group affect the use of a bank representative in a shop, and this enables bank customers to conveniently access local banking services. This finding is similar to the research results showing that career impacts banking agent selection; however, this study also focuses on marital status and savings as important factors in choosing a bank agency. Users with low incomes can make transactions through bank representatives without having to waste time and travel expenses even though this investigation found that income does not affect the use of a bank agency, although savings does.

According to the opinion of Sandec Wycliffe (2012 refer to Mwende et al., 2015), banking agents and systems make banking more convenient for customers, particularly regarding traveling, as when a large number of customers use the services there can be long waiting times. Additionally, customers who use the services must also consider transportation costs. However, since 2010, significant service improvements have been made in the banking sector by launching a bank representative. Financial service delivery channels are an innovation allowing people in remote areas to access financial services. Agent banks could reduce the cost of delivering financial services to people in remote locations. One of the problems regarding access to financial services is that banks are not necessarily located near the customers; therefore, the customers need to travel long distances to access banking services and people living in remote areas outside the banking system are unable to access services. The solution is taking advantage of third-party agency networks as a banking agent, reducing the cost of transaction management and being available for services such as cash transactions and account opening (Lyman, et al, 2008)

According to the conclusion of Ivantury and Timothy (2006), bank customers receive three benefits: a reduction in transaction costs, longer opening hours and shorter distances to banks, allowing people in remote areas to use the services. In order to increase access to banking services and to define the bank products offered by the agent banks, it is acknowledged that most respondents (86\%) strongly agree that the bank agency is more costeffective in providing banking services to customers and this saves time because customers do not need to travel long distances (Mwende et al., 2015)

This study's findings relate to Saeju (2018), which explain that appointing convenience stores as banking agents is highly beneficial for clients residing in remote areas because the clients could access banking activities at the closest banking agent store; therefore, they do not need to visit distant bank branches resulting in the decreasing cost of establishing new branches and cash delivery. In addition, Sajjapong (2018) state that even though the aim of appointing the banking agents is to provide smooth and convenient services for the clients, its processes have to be conducted under the strict guidelines and conditions of the Bank of Thailand, so the official banking agents are the ones who have got the perfect qualifications to meet the requirements of the banking agent guidelines. 


\section{Recommendations}

Policy recommendations: Since opinions of the banking agent play an important role in this study, financial institutions must ensure that the safety policies of the banking agent for their clients are of the same standards as those of the appointing financial institutions.

Academic recommendations: Further studies are recommended to observe the population in different age groups, particularly elders because this generation tends to be ignored and so they might struggle in a digital world. Since the acceptance of financial transactions through banking agents could grow in the older population, it is assumed that there might be an increase in senior users in this banking method.

\section{Acknowledgment}

This study was accomplished because of supports from Asst.Prof.Tanpat Kraiwanit, Ph.D, the supervisor of this research, who gave advises, guidelines and corrected any mistakes until this article was completed perfectly. I am appreciated for all helps.

\section{References}

Bank of Thailand. (n.d.), "Rules for service channels for commercial banks", available at: https://www.bot.or.th/rhai/AboutBOT/Activities/Documents/ Banking - license - Slide.pdf. (accessed on 3 November 2018).

Bock, T. (2018), "What are Variance Inflation Factors (VIFs)?" available at: https://www.displayr.com/variance-inflation-factors-vifs/. (accessed on 3 November 2018),

Boonterm. (2015(. available at: http://www.boonterm.com/web/news_detail.php?id=239 (accessed on 3 November 2018).

Bruin, J. (2006), "Newtest: command to compute new test". UCLA Statistical Consulting Group. https://stats.idre.ucla.edu/stata/ado/analysis/. (accessed on 3 November 2018).

CGAP. (2012), ."Understanding Branchless Banking Business Model International Experience". Focus Note, (43), Washington D.C.

Ivatury, G., and Lyman, T. (2006),"Use of Agents in Branchless Banking for the Poor: Rewards, Risks, and Regulation“. Focus Note, 38, Washington D.C: CGAP.

Lyman, T, Pickens, M. and Porteous. D. (2008), "Regulating Transformational Agency Banking: Mobile phones and Other Technology to Increase Access to Finance". Focus Note, 43, Washington, D.C.: CGAP

Malek, B. A., Mohtar, S., Ariffin, A. S. (2017), "The factor that affects the effectiveness of agent banking characteristics on financial inclusion performance: A study from Malaysian government-owned banks in Negeri Sembilan“, Journal of Advanced Research in Business and Management Studies 7, Issue 1, pp. 91-102.

Mwende, M. J., Bichanga, J., and Mosoti, J. (2015), "Investigation on Importance of Agency Banking in Provision of Banking Services in Kenya:(A Case of Equity Bank) in Kitui Central District, Kitui County, Kenya“. International Journal of Scientific and Research Publications.

Saeju, D. (2018), "The Bank of Thailand Offering a New Option, Appointing Convenient Stores as Banking Agents", available at: https://techsauce.co/fintech/bank-of-thailand-changed-the-rulesfor-convenience-store (accessed on 3 November 2018).

Sanguanprasit, C. (2018), "what will happen? When 7-ELEVEN deposits - withdraw money like banks starting at 1 bah" available at: https://brandinside.asia/money-7-eleven-deposit-gsb/. (accessed on 3 November 2018). 
Sajjapong, S. (2018), "The BOT is ready to open a banking agent. It is expected to be used in Q1 / 61, Believing helps stimulate spending - looking at CPALL is appropriate". available at https://www.ryt9.com/s/iq05/2784548. (accessed on 3 November 2018).

Thairathonline. (2011), "Thai Post Office "cooperate with 6 banks, deposit-withdrawal agents", available at: https://www.thairath.co.th/content/166968. (accessed on 3 November 2018).

TermSabyeplus. (n.d.(. available at: http://termsabuyplus.com/termsabuy-plus/ 